\title{
Alfonso Reyes y José Ortega y Gasset: una amistad reacia, un largo malentendido*
}

Fecha de entrega: 20 de marzo de 2019

Fecha de evaluación: 31 de marzo de 2020

Fecha de aprobación: 13 de abril de 2020

\author{
Juan Granados Valdéz $z^{* *}$
}

\section{Resumen}

La influencia de José Ortega y Gasset en el pensamiento mexicano ha sido estudiada con detalle, pero no así la relación que guardó con el insigne literato y diplomático mexicano, don Alfonso Reyes. En este artículo se muestra, desde la perspectiva del pensador regiomontano, esa reacia amistad o ese largo malentendido que se dio entre Reyes y el filósofo español. En el texto se da cuenta minuciosamente de la presencia de Ortega y Gasset en México, gracias a la ayuda de Reyes. Esta relación no solo se detiene en las influencias intelectuales, sino que va hasta el encuentro personal, en donde se identifica la circunstancia que hace a cada uno.

Palabras clave: circunstancia, pensamiento mexicano, cultura hispanoamericana, América, literatura, Ortega y Gasset.

* Este artículo es resultado de las investigaciones adelantadas por el autor en torno a la filosofía y la estética. Citar como: Granados Valdéz, J. (2020). Alfonso Reyes y José Ortega y Gasset: una amistad reacia, un largo malentendido. Cuadernos de Filosofía Latinoamericana, 41(123), 77-98. Dol: https:// doi.org/10.15332/25005375/5068

* Profesor de tiempo completo en la Facultad de Bellas Artes de la Universidad Autónoma de Querétaro, México. Correo electrónico: juan.granados@uaq.mx 


\section{Alfonso Reyes and José Ortega y Gasset: A Reluctant Friendship, a Long Misunderstanding}

\section{Abstract}

The influence of José Ortega y Gasset on Mexican thought has been studied in detail, unlike the relationship he had with the distinguished Mexican literate and diplomat Don Alfonso Reyes. Taking the perspective of the Monterrey thinker, this article gives an account of the reluctant friendship - or long misunderstanding - he cultivated with the Spanish philosopher and reveals the details of Ortega y Gasset's stay in Mexico, which was made possible thanks to Reyes' help. Their relationship was not limited to intellectual influences, but was enriched by personal encounters, where the circumstance that made up each one of them may be identified.

Keywords: Circumstance, Mexican Thought, Spanish American Culture, America, Literature, Ortega y Gasset.

\section{Introducción}

En el marco de una investigación sobre la obra Alfonso Reyes, surgió la pregunta general sobre la influencia de José Ortega y Gasset en México y, después, en particular, por su influencia y relación con el literato regiomontano. La relación que mantuvieron estos intelectuales revela una faceta poco conocida de Ortega y Gasset, que confirma que era él y su circunstancia, cosa que también aplica al pensador mexicano. Y he aquí la justificación y la metodología de este estudio: la aplicación histórico-biográfica de la fórmula orteguiana, "Yo soy yo y mi circunstancia", al caso de la relación que mantuvo con Reyes. Así pues, el propósito de este trabajo es indagar en esa relación y analizar cómo se convirtió en una amistad reacia y en un largo malentendido.

\section{La influencia de Ortega y Gasset en México}

La influencia de Ortega y Gasset en México es innegable. En 1987, José Luis Gómez Martínez publicó en la Nueva Revista de Filología Hispánica su estudio “La presencia 
de Ortega y Gasset en el pensamiento mexicano" (Gómez Martínez, 1987). El texto está dividido en seis partes, a saber, una introducción y cinco apartados que llevan por título: "1. México en la década de la Revolución”; "2. Toma de conciencia y recuperación de la circunstancia mexicana"; "3. Ortega y Gasset y la circunstancia mexicana"; “4. El Ortega mexicano”; “"5. Presencia de Ortega en México”.

De acuerdo con Gómez Martínez, hay tres Ortegas en el desarrollo del pensamiento mexicano e hispanoamericano. Para Francisco Romero, Ortega y Gasset representaba un "jefe espiritual”, un líder intelectual con una gran influencia simbolizada, sobre todo, por su labor en torno a la Revista de Occidente. Por medio de esta publicación, dice Samuel Ramos, "los estudiosos de México se pusieron en contacto con el pensamiento alemán contemporáneo y se despertó el interés por leer las obras de sus grandes filósofos" (Ramos, 1976, p. 227). Este es el primer Ortega y Gasset. El segundo es el autor de Meditaciones del Quijote, El espectador, El tema de nuestro tiempo, Ideas y creencias e Historia como sistema, además de otros ensayos, quien será el más influyente en el desarrollo de una filosofía de lo mexicano. De acuerdo con Gómez Martínez, este Ortega y Gasset posibilitó, junto con Samuel Ramos, Edmundo O’Gorman y Leopoldo Zea, llevar el pensamiento mexicano a niveles de creación filosófica. No obstante, a pesar de su influencia, Ortega y Gasset fue combatido por los neo-escolásticos y los neo-kantianos (mexicanos), de quienes Gómez Martínez no menciona nombres. El tercer Ortega y Gasset es el autor de La deshumanización del arte, Ideas sobre la novela, La rebelión de las masas y otros ensayos, quien fue ignorado o combatido en México, según Gómez Martínez.

Aunque no se cuenta con datos sobre la llegada de las obras de Ortega y Gasset a México, según Gómez Martínez (1987) puede afirmarse que para 1916 ya se tenía noticia de él y para 1922 su obra comenzó a ser discutida en los círculos culturales. La difusión se dio, en un periodo inicial, gracias a Alfonso Reyes, quien en 1922 escribió sus “Apuntes sobre José Ortega y Gasset”, incluidos en su libro de 1923 Los dos caminos.

Las primeras obras de Ortega y Gasset en México fueron sus Meditaciones del Quijote y los tres primeros volúmenes de El espectador. La llegada de estas obras coincide con la circunstancia del fin de la Revolución mexicana y las primeras manifestaciones culturales (en las artes, la educación, etc.) de una nueva conciencia del mexicano, por parte del pueblo y los intelectuales. Su postulado "Yo soy yo y mi circunstancia, y si no 
la salvo a ella no me salvo yo" (Ortega y Gasset, 1964, p. 30) y la afirmación de que "el hombre rinde el máximo de su capacidad cuando adquiere la plena conciencia de sus circunstancias. Por ellas se comunica con el universo" (Ortega y Gasset, 1964, p. 25), en las Meditaciones del Quijote, calaron hondo en los (intelectuales) mexicanos que no necesitaron largas explicaciones para comprender unos postulados teóricos que ya practicaban. La pintura mural sería un buen ejemplo de ello. Los mexicanos, pues, podían hacer lo mismo que decía Ortega y Gasset. Puesto que "la realidad no puede ser mirada sino desde el punto de vista que cada cual ocupa, fatalmente, en el universo. Aquella y este son correlativos, y como no se puede inventar la realidad, tampoco puede fingirse el punto de vista" (Ortega y Gasset, 1966, p. 23), como dice Ortega y Gasset en El espectador, los mexicanos intentaron describir el mundo desde su punto de vista. En la historia de México se había vivido y actuado a la saga del punto de vista europeo y ahora se estaba en condiciones de recuperar la propia perspectiva en todos los ámbitos de la cultura.

Ramos, en 1943, en su Historia de la filosofía en México, “el primer estudio sistemático sobre el desarrollo del pensamiento mexicano", según Gómez Martínez (1987), incluye una sección titulada "La influencia de Ortega y Gasset". El postulado "Yo soy yo y mi circunstancia, y si no la salvo a ella no me salvo yo" es considerado por Ramos como la piedra angular sobre la cual se edificó la filosofía de lo mexicano (Ramos, 1976, pp. 96-231). Él mismo reconoce su deuda con Ortega y Gasset (Romanell, 1952; $1960 ; 1975)$.

Esta apreciación de Ramos, que recogen y proyectan después José Gaos y los miembros del Grupo Hiperión [Joaquín MacGregor, Octavio Paz, Jorge Portilla, Emilio Uranga, Luis Villoro y Leopoldo Zea], ha llegado a ser hoy día lugar común en las evaluaciones y exposiciones del desarrollo del pensamiento mexicano. (Gómez Martínez, 1987, p. 197)

No obstante, no se ha analizado esta influencia, por ejemplo, en lo que se refiere a los postulados que fueron aceptados y/o rechazados, ni a las razones que motivaron hacer lo uno o lo otro.

De acuerdo con Solomon Lipp, por ejemplo, "la influencia de Ortega en el pensamiento de Zea es indiscutible” (Lipp, 1980, p. 131), no obstante, Leopoldo Zea se mostró crítico de Ortega y Gasset. En su ensayo “Ortega americano” dice lo siguiente: 
José Ortega y Gasset, alguna vez, declaró a nuestro Alfonso Reyes el agrado que tendría de ser apodado Ortega el americano, como se dijo en la Antigüedad Escipión el africano. Y he aquí que por lo que su obra representó para nuestra América, la hispánica, Ortega merece este apodo; pero a pesar suyo. Y digo a pesar suyo porque, independientemente de esa declaración, la simpatía de Ortega por América fue siempre limitada, llena de prevenciones. De la América hispana solo conoció la Argentina y se resistió siempre a entrar en contacto con el resto de ella. (Zea, 1956, p. 132)

Las últimas palabras de Zea, "solo conoció la Argentina y se resistió siempre a entrar en contacto con el resto de ella", nos sirven de advertencia a una concesión acrítica y acircunstancial con Ortega y Gasset.

\section{Jorge Luis Borges, amarranavajas}

Dejaré de lado el análisis sugerido por Gómez Martínez sobre la recepción de los postulados orteguianos para detenerme en la relación entre Ortega y Gasset y Reyes, de la cual ya he adelantado un par de cosas, con su ayuda. A Reyes se debe, al menos en el comienzo, la difusión del pensamiento de Ortega y Gasset con sus “Apuntes sobre José Ortega y Gasset”, publicados en 1923; y a él, pues, le declaró Ortega, como dice casi de pasada en su libro La última Tule, que le agradó el apodo de "Ortega el americano", después de su primer viaje a Argentina, como también recuerda Zea. Pero la relación con Ortega y Gasset va más allá de esto.

En febrero de 2013, en la capilla Alfonsina, se presentó la reedición del libro de Adolfo Castañón (1952), Alfonso Reyes, caballero de la voz errante, cuya primera edición se publicó en 1988. El libro trata, entre otras cosas, de la amistad reacia que mantuvo Reyes con Ortega y Gasset. En 2010, en un artículo publicado en la revista Letras Libres, Castañón insistió en lo mismo. Carlos García en el 2000 y luego en el 2006 reafirmó, en dos estudios, que entre Reyes y Ortega y Gasset hubo un "largo malentendido". Quise recuperar las expresiones "una amistad reacia” de Castañón y "un largo malentendido" de García para el título de este artículo, con el propósito de indicar que lo que viene es polémico y que, probablemente, no va a gustar, sobre todo porque hay una cierta estima indudable por Ortega y Gasset, que lo mantiene entre las lecturas frecuentes de estudiantes y profesores de filosofía, y porque hace unos años se festejó el aniversario de los cien años de la publicación de las Meditaciones del Quijote de 
este filósofo español. Pero viene a cuento hablar sobre esa amistad reacia y ese largo malentendido porque en 1914, llegado a Madrid, un año después de la publicación de la obra orteguiana, Reyes conoció al filósofo español, y dos años después escribió sus primeros apuntes, que más adelante expondré.

El motivo para hablar del "largo malentendido" y la "reacia amistad", empero, para este estudio, lo encontré en la recopilación que hace Felipe Garrido, titulada La máquina de pensar y otros diálogos literarios, con ocasión del Día Internacional del Libro de 1998, en la que reúne textos de Reyes y Borges sobre temas en común. Entre los últimos, para no detenerme en la descripción de la edición, viene la transcripción de una entrevista hecha al literato argentino y que se publicó en 1973 en el número 28 (abril-diciembre) del Boletín de la Capilla Alfonsina, y que lleva por título "Cómo conocí a Alfonso Reyes”. Allí dice Borges:

Recuerdo una tarde que conversé con él, no, una noche tiene que haber sido, porque nos veíamos de noche los domingos, en la Embajada de México. Recuerdo que él estaba indignado por un juicio más o menos ligero y atolondrado de Ortega y Gasset sobre Goethe. Goethe era uno de los dioses de la devoción de Alfonso Reyes. Entonces, él formuló varias objeciones y yo le dije que por qué no las escribía. Y, entonces él, con genuino estupor, me dijo: “¡Pero cómo voy a polemizar con Ortega y Gasset!”. Yo le dije: “Pero todos sabemos que usted es infinitamente superior a Ortega y Gasset".

Pero él no podía admitir eso; siempre se sentía en actitud de discípulo ante escritores que eran ciertamente inferiores a él. Por ejemplo, el tono de reverencia que tenía cuando hablaba de Azorín. Luego él encontró una salida: escribió un libro sobre Goethe, publicado por el Fondo de Cultura Económica en México. Ese libro viene a ser una respuesta a Ortega y Gasset. Pero él no se refiere nunca directamente a Ortega y Gasset. Ahora, aquí pueden haber influido dos cosas: por un lado, cierta timidez, porque creo que Reyes - a pesar de ser valiente y me consta que fue valiente- era tímido. Y también la cortesía, porque a Reyes no le gustaba disentir de su interlocutor. Y como era infinitamente inteligente, esto lo sabemos todos, a veces hasta inventaba razones a favor de su interlocutor y contra sus propias convicciones. (Borges, 1998, pp. 147-148) 
Al margen de lo que en otras ocasiones dijera el autor de El Aleph sobre Reyes, en esta intervención suya, reconoce su valentía y su inteligencia, lo mismo que su timidez y su cortesía. Me llama la atención, empero, que Borges notara la indignación de Reyes y calificara el juicio de Ortega y Gasset sobre Goethe de "más o menos ligero y atolondrado"; asimismo, contra el estupor de Reyes de escribir sus objeciones y polemizar con el filósofo español, Borges le dice que "todos sabemos que usted es infinitamente superior a Ortega y Gasset" y que complementa más adelante con el juicio de que Reyes "era infinitamente inteligente". Aunque llegó la respuesta a Ortega y Gasset por parte de Reyes, con su libro La trayectoria de Goethe y otras obras de 1953 y 1954, Borges nota que nunca menciona al filósofo español, para evitar, quizá, la polémica. Pero sí la hubo. Se abrió algo así como "el caso Goethe” en el que se involucraron, entre otros, el argentino Eduardo Mallea y la española María Zambrano, como constatan Castañón (2006) y Alberto Enríquez Perea (2006) ${ }^{1}$.

Pero como todo tiene un inicio y estamos aquí con ocasión de la publicación de las Meditaciones del Quijote, antes de volver a las palabras de Borges sobre Reyes, Goethe y Ortega y Gasset, y, quizás echar de nuevo algunas gotas de limón a la herida, al menos simbólica e imaginativamente, repasemos el contexto de la relación entre el mexicano, llamado universal, y el filósofo perspectivista y raciovitalista español.

\section{Reyes en la España de Ortega y Gasset}

En 1913, después de obtener el título profesional de abogado, Reyes fue enviado a París, primero como comisionado ad honorem de la Secretaría de Instrucción Pública de México en Francia (12 de julio de 1913) y después como segundo secretario de la legación mexicana en Francia (julio de 1913-octubre de 1914). Recién había ocurrido la "decena trágica" en la que murió su padre, el general Bernardo Reyes, y de la que da cuenta en su "Oración del 9 de febrero", que concluye con el derrocamiento y la muerte de Madero y la posesión de Victoriano Huerta como nuevo presidente de México. Sobrevienen, empero, dos acontecimientos que obligan a Reyes a salir de Francia

1 Enriquez Perea (2006), por ejemplo, en su estudio preliminar a la compilación que hace de la correspondencia (setenta cartas) entre María Zambrano y Alfonso Reyes en un lapso que va de 1939 a 1959, titulada Días de exilio, incluye "Entre el fuego divino de Goethe", un apartado con ocasión de dos cartas que dirigió Zambrano a Reyes por las dos publicaciones sobre Goethe que hizo el autor de El deslinde a principios de los años cincuenta. 
y radicarse en España: la Primera Guerra Mundial y el triunfo de Venustiano Carranza, quien suspendió en masa el cuerpo diplomático y consular mexicano en el extranjero.

En 1914 inició la Primera Guerra Mundial, Estados Unidos bloqueó a México y sus fuerzas navales desembarcaron en Tampico. Carranza y Obregón derrocaron a Huerta; Carranza se autonombró Primer Jefe del Ejército Constitucional y Zapata y Villa se le opusieron. Mientras tanto, Reyes llegaba a Burdeos con su mujer y su hijo. Luego fueron a San Sebastián y se establecieron durante un tiempo, por último, se instalaron en Madrid. En esta ciudad, Reyes entabla una amistad con Enrique Díez-Canedo y Juan Ramón Jiménez, y trabaja, durante cinco años, en el Centro de Estudios Históricos de Madrid, en la sección de filología, bajo la dirección de Ramón Menéndez Pidal. Tuvo como compañeros de sección a Américo Castro, Federico de Onís, Tomás Navarro, Antonio Solalinde y otros. Reyes se consagró a la literatura y al periodismo. Se convirtió en colaborador de planta de la Revista de Filología Española del mismo Centro.

En 1915, Reyes escribió la Visión de Anáhuac (cumbre de la literatura en lengua española). En 1917 se promulgó la Constitución Mexicana. En 1919 asesinaron a Zapata. En 1920, cuando fue asesinado Venustiano Carranza y fue electo presidente Álvaro Obregón, Reyes fue nombrado secretario de la Comisión Mexicana Histórica Francisco del Paso y Troncoso, bajo la dirección de Francisco A. de Icaza, destinada a investigaciones históricas nacionales en los archivos de Europa. En 1920 se reintegró a la diplomacia en la legación de Madrid con el nombramiento de segundo secretario de la legación mexicana en España. Durante estos años Reyes colaboró con diarios y revistas tanto españoles como de otros países, entre los que se encuentran $\mathrm{El} \mathrm{Sol} \mathrm{y}$

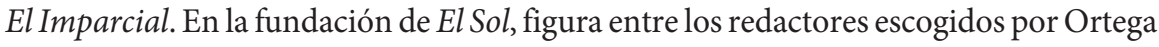
y Gasset, y se encargaba de la página semanaria de los jueves, "Historia y Geografía", consagrada a temas humanísticos generales. El quinto tomo de la Obra completa de Reyes incluye las obras Historia de un siglo y Las mesas de plomo. Aunque ambos son libros corregidos y aumentados con el tiempo, los dos incluyen textos redactados por Reyes para su publicación en El Sol entre 1918 y 1920 sobre las historias del siglo xIx y el periodismo europeo, respectivamente (Reyes, 1995b). Esta participación en el periódico realmente marcó su actividad madrileña. Así lo cuenta Reyes en el prólogo al quinto tomo de su Obra completa (firmado en 1952):

Tuve a mi cargo durante algún tiempo una página de geografía e historia que aparecía todos los jueves en El Sol de Madrid. Cuando José Ortega y Gasset 
—inspirador del periódico - me hizo el honor de invitarme junto a otros amigos, para que entre todos nos distribuyéramos semanariamente las distintas ramas del estudio y la información — la economía, la educación, la medicina, las artes, etc.-, yo no vacilé en aceptar, porque, me dije, cuanto acontece en el tiempo es historia, y en el espacio, geografía. (Reyes, 1995b, p. 11)

El Imparcial publicó sus crónicas cinematográficas a petición del mismo Ortega y Gasset. Paralelamente a sus trabajos periodísticos, Reyes realizó las traducciones y ediciones que Calleja le encargó para su colección de clásicos populares.

\section{El primer Ortega y Gasset de Reyes: "Apuntes sobre José Ortega y Gasset"}

A partir de las bases histórico-biográficas de esta primera etapa de Reyes, queda ir al detalle y afinar la lupa. A Reyes se debe, ya lo adelantaba, la difusión del pensamiento de Ortega y Gasset con sus “Apuntes sobre José Ortega y Gasset” y a él, pues, le declaró el pensador español que le agradó el apodo de "Ortega el americano" después de su primer viaje a Argentina. Insisto en esto de nuevo, porque lo que viene lo hará explícito. Los “Apuntes...” (Reyes, 1995a) de Reyes son tres. El primero, "Crisis primera: la salvación del héroe", fue escrito en 1916; el segundo, "Crisis segunda: nostalgias de Ulises”, en 1917; y el tercero, "Crisis tercera: melancolías de Fausto”, en 1922. Los tres se publicaron, como mencioné, en Los dos caminos (1923).

En "Crisis primera: la salvación del héroe", Reyes afirma que Ortega y Gasset destaca con gesto paladín entre la juventud española. Es el héroe, dice. Sin embargo, en él encuentra una bifurcación interna, una doble vocación que comparte su actividad: la oficial y la personal. La oficial es la del catedrático de filosofía y la personal es la del literato. Aunque no demerita su capacidad de filósofo, Reyes dice que prefiere al literato porque

[...] si como literato Ortega y Gasset ve las cosas humanas bajo especies cálidas y concretas, y las expresa con un ánimo de belleza, como filósofo quisiera ceñir su conducta intelectual dentro de una sola tendencia, coordinarla con su conducta práctica y construir, a través de la palabra, algo como un nuevo ideal 
de España, cuya última manfiestación [sic] tendría que ser la obra de reforma política. (Reyes, 1995a, p. 258)

Esto queda de manifiesto en Vieja y nueva política, de 1914, destaca Reyes, en donde Ortega y Gasset, el héroe, convoca a los jóvenes a ensayarse en la vida pública, a obrar en la primera oportunidad, a echarse a la calle en la primera ocasión, aunque sea en mangas de camisa. Reyes se percata, empero, que para quien, al gusto platónico, medita demasiado la acción, deja pasar las oportunidades y las ocasiones, así pues "los jóvenes [...] siguieron estudiando con los libros abiertos". En las Meditaciones del Quijote, también de 1914, Reyes reconoce que Ortega y Gasset se propone "un fin esencialmente político": en sus Meditaciones, vistas hasta lo más íntimo y personal (siguiendo las palabras del mismo Ortega), pueden verse "experimentos de nueva España” que niegan la vieja. Pero, según Reyes,

[...] este propósito parece como sobrepuesto al libro artificialmente, como adaptado desde afuera para organizar una serie de ensayos sueltos, para convertir en tesis un montón de artículos varios. De donde resulta, por ejemplo, que, a fin de aprovechar una página sobre los “conceptos", el autor se ve obligado a justificarse. (Reyes, 1995a, p. 259)

¿Una teoría de los conceptos es también un menester nacional?, se pregunta Reyes. Por si fuera poco, sigue contando que en 1915 funda la revista semanaria España, un órgano de actividad política, pero pronto el director se alejó de su revista y, sin romper con ella, se dedicó, mejor, a la literatura, "a escribir en casa sobre los asuntos que le plazca”. Es un jefe de partido algo indiferente y un excelente literato. La filosofía, dice Reyes, llevaba en esa época a Ortega y Gasset por la pendiente de la política, mientras que la literatura lo emancipaba de todo lo que no fuera Dios. Finalmente, está El espectador, con el que la vocación personal le juega una mala pasada a la política: "revista 'espectacular', como lo indica su nombre, de libres desahogos mentales, de ensayos sobre todas las cosas de este mundo y del otro, sin propósitos prácticos artificiales, sin sistema político alguno” (Reyes, 1995a, p. 259). El libro parece volver la espalda a sus propósitos anteriores. Reyes, sobre esto, hace una comparación: “Como el joven Descartes después de sus viajes, Ortega y Gasset, al regreso de sus primeras excursiones por la vida pública, vuelve a sus afanes estudiosos y a la investigación de sí mismo” (Reyes, 1995a, p. 260). El espectador es un gesto de emancipación de la política, esa que se caracteriza por la supeditación de la teoría a lo útil. ¿Hay contradicción en Ortega 
y Gasset?, se pregunta el pensador regiomontano. No, se responde, sino la salvación del héroe. Salvación de la política, se entiende, por un momento si se quiere, porque, como pasará, Ortega y Gasset descenderá, otra vez, a la política española.

En "Crisis segunda: nostalgias de Ulises", Reyes dice que el segundo tomo de El espectador es otro alto en el proceso que describe, pero el viraje no es nada feliz: "este segundo volumen de El espectador está preñado de amargura. Y escribir a fuerza de dolor es el peor método de arte" (Reyes, 1995a, p. 263). Este alto lleno de amargura queda determinado por la visita de Ortega y Gasset a América: "El viaje a América determina, en Ortega y Gasset, una honda y fecunda crisis" (Reyes, 1995a, p. 261), declara el pensador regiomontano. Esta honda y fecunda crisis tendrá que ver con la decepción de Ortega y Gasset con España. Reyes lo constató, sobre todo, por la visita a Argentina: "En su reacción contra los males o peligrosos ambientes, Ortega y Gasset se ha ido amargando, se ha ido despechando de España". Y esto se debe, según Reyes a que

[...] el viaje de América ha dado rumbo nuevo a esta investigación de sí mismo que embarga la atención de Ortega. Porque este escritor se busca a sí mismo, sin cesar, con una inquietud de adolescente. Hay en él un yo no sé qué de niño heroico, que pone una vida sin malicia al servicio de una idea terrible. El viaje a América no fue para él un viaje de recreo. Creyó descubrir en aquellas sociedades, que comienzan, con efervescencia, una nueva historia, el antídoto contra las dolencias de las sociedades caducas; creyó descubrir nuevas alegrías posibles, una existencia más amplia y digna, una mejor acogida para la obra del pensador; una posible rectificación total de las viejas equivocaciones; la probabilidad de recomenzar una vida más conforme con nuestra idea. En suma: podemos decir, con una sonrisa, que José Ortega y Gasset descubrió a América. (Reyes, 1995a, p. 261)

La descubrió para sí mismo. Se entusiasmó por la Argentina y se decepcionó más de España. No obstante, dice Reyes, “yo temería que su entusiasmo por América estuviese también llamado a desvanecerse, como se ha desvanecido aquel hermoso sueño de reconstrucción de la patria, que inspiraba en otro tiempo las páginas de las Meditaciones" (Reyes, 1995a, p. 262). Este temor se funda en que Reyes entiende que la América de Ortega y Gasset es limitada, pues se reduce a Argentina, que para ese 
momento representaba la América feliz, la de las Gracias, que ríe y que juega (Reyes, 1995a, pp. 262-263), como dice él. Por eso el autor de la Visión de Anáhuac preguntaba:

[...] si a nuestro escritor ha podido seducirle la América que ríe y que juega, ¿podría seducirle igualmente la América que llora y combate? Ha admirado el músculo en reposo, la belleza estatuaria de la línea que se recrea en su quietud robusta. ¿Admiraría igualmente el músculo que se contrae bajo el agobio de un duelo nacional? [...] [i]también en América hay lágrimas para las desgracias! A medida que se sube hacia el Norte, la América nuestra va dejando ver sus entrañas. (Reyes, 1995a, p. 263)

A estas alturas Ortega y Gasset es un Ulises que no termina de llegar de su viaje a la Ítaca prometida, o que llegando no ha encontrado lo que esperaba o que llegando recuerda las promesas de las sirenas. En fin, Reyes, con esperanza y buen ánimo, nos insta al final de este segundo apunte a no pedir demasiado de los otros ni de uno mismo, a aguardar el restablecimiento de la alegría contra la amargura en el pensador español.

Ahora bien, Ortega y Gasset, como se sabe, hizo tres viajes a Argentina. El primero en 1916 con su padre. Este viaje tuvo por objeto ocupar la cátedra creada por la Institución Cultural Española en la Universidad de Buenos Aires (7 de julio-16 de febrero). Mientras tanto, en Madrid nació su tercer y último hijo, José, el 13 de noviembre. Publicó, también en este año, el primer volumen de El espectador. El segundo viaje lo hizo en 1928 para dictar un curso en la Facultad de Filosofía y Letras de la Universidad de Buenos Aires. El tercer viaje sucedió en 1939, realizado con su esposa y su hija Soledad. Permaneció tres años en Buenos Aires. El segundo apunte sobre Ortega y Gasset es la primera nota de Reyes sobre el primer viaje del filósofo español a Argentina. Hubo otras menciones. En el apartado cuarto, "La verdadera España”, del ensayo XII, "Significado y actualidad de 'Virgin Spain”, firmado en 1941, incluido en La última Tule ${ }^{2}$, Reyes mencionó que

Después de su primer viaje a la Argentina, José Ortega y Gasset —que ya antes había declarado que América era el mayor honor y la mayor responsabilidad histórica de España- me confesó que le agradaría ser apodado “Ortega el

2 En la geografía romana y medieval, Última Thule podia denotar cualquier lugar distante situado más allá de las fronteras del mundo conocido. 
americano", como se dijo en la Antigüedad: "Escipión el africano". (Reyes, 1997, p. 148)

Sobre el primer viaje a Argentina y las consecuencias que conllevó en Ortega y Gasset, Reyes consignó sus impresiones en Simpatías y diferencias. Tzvi Medin, en su Ortega y Gasset en la cultura hispanoamericana (Medin, 1994, pp. 22-24), recupera las ideas de Reyes para darle la razón sobre la decepción de Ortega y Gasset con España, pero no solo a partir de su viaje, pues el filósofo español ya estaba decepcionado de su tierra de antemano.

En "Crisis tercera: melancolías de Fausto", a modo de síntesis, Reyes hace un balance del itinerario vital e intelectual de Ortega y Gasset: de inquietador de la juventud a espectador y de espectador a Fausto joven. Dice: "Ortega y Gasset — como un Fausto todavía joven, pero ya con cierta trágica inquietud- cierra un instante el libro y alarga las manos hacia la imagen (¡ay, hacia la imagen voluble!) de la vida” (Reyes, 1995a, p. 265). Reyes considera que es ejemplo de vida, la faceta de viajero de Ortega y Gasset, siempre a la saga de lo que "no se encuentra en las costas de la tierra" (Reyes, 1995a, p. 265). Con este apunte termina el comentario de Reyes a las primeras obras del filósofo español. Este llamamiento a aprender del viajero Ortega quizá fue el que llamó la atención de los intelectuales mexicanos que empezaron a leerlo a instancias del literato regiomontano, como ya decía Gómez Martínez.

\section{Una reacia amistad: inicio del largo malentendido}

Sigamos, pues, el camino que iniciamos, después de los comentarios. En 1921, Reyes publicó El cazador, El plano oblicuo, Calendario y Vísperas de España. En 1922, escribió sus “Apuntes sobre José Ortega y Gasset”, publicados en 1923 en Los dos caminos. Entre 1922 y 1924 fue encargado de negocios en España. En 1924, cuando Plutarco Elías Calles ocupaba la presidencia de México, Reyes publicó su Ifigenia cruel (poema dramático). En este año regresó a México por un corto periodo. Finalmente, fue nombrado ministro en Francia hasta 1927.

“Al salir de España está relacionado con Azorín, Ortega y Gasset, Unamuno, Valle Inclán, Navarro Tomás y Menéndez Pidal”, dicen las biografías y cronologías sobre Reyes, incluida la que hace su propia nieta, Alicia Reyes. No ocurre, empero, lo mismo con las biografías y las cronologías de Ortega y Gasset. En la biografía de José Lasaga 
Medina (2003), José Ortega y Gasset (1883-1889). Vida y filosofía, por ejemplo, no hay una sola mención a Reyes, ni en la biografía, ni en la cronología ni en la bibliografía. Por mera curiosidad, quien sí aparece citado es el premio nobel mexicano de literatura, Octavio Paz (1974), con su “José Ortega y Gasset: el cómo y el para qué” en Hombres en su siglo.

Reyes regresó a México desde Francia en $1927^{3}$. Tenía 37 años. Viajó en el barco Espagne de la Compañía Trasatlántica. Es una celebridad en Francia. Lo despiden entre banquetes y festejos, amigos y conocidos, entre ellos la poeta Gabriela Mistral. Fue convocado a México para encargarle una misión diplomática compleja y delicada, para la que solo él era capaz (dicen sus biógrafos): abrir en Argentina una embajada y reanudar los lazos que se descuidaron con la Revolución. En Argentina se encontró con Victoria Ocampo y se reencontró con Pedro Henríquez Ureña. Estableció amistad con jóvenes escritores, entre ellos el joven de 28 años, Jorge Luis Borges; y fundó la colección de los Cuadernos del Plata y la revista Libra, de la que solo salió un número. En Argentina, Victoria Ocampo invitó a Ortega y Gasset a dar un conjunto de conferencias en 1928 sobre "El peligro de nuestro tiempo". Este paso del filósofo español por Buenos Aires representó para Reyes un sinsabor.

En su Anecdotario inédito (1914-1959), el mexicano universal refiere ocho anécdotas sobre Ortega y Gasset durante su segunda visita a Argentina y su encuentro en Buenos Aires (Reyes, 1994, pp. 396-399). Estas son el reflejo de la relación amistosa que tenían por ese entonces, nacida mucho tiempo atrás, en Madrid, cuando Ortega y Gasset apoyó a Reyes y se hicieron amigos: "fue su amigo casi íntimo, al grado de que Reyes le prestó las llaves de su apartamento de soltero en Buenos Aires para asuntos

3 "El 21 de marzo de 1927 Alfonso Reyes regresa a su país de origen desde la embajada en Francia. Sale de París con su familia muy de mañana rumbo a México, luego de haber sido objeto de banquetes y despedidas, atenciones y deferencias innumerables por parte del gobierno, la buena sociedad y la inteligencia francesa. Las últimas personas a las que ve en la víspera de su partida, el 20 de marzo de 1927, son la poeta Gabriela Mistral y la diplomática Palma Guillén. 'Muy de mañana' (8:37 a. m.) toma el tren en la estación del Quai d'Orsay - actualmente transformada en museo- hacia Saint-Nazaire, donde abordará un barco que lo Ileve a Veracruz, México, pasando por Santander y La Habana. Ha pasado dos años como embajador de México en París, luego de haberse reintegrado al servicio diplomático en 1921 y después de haber sobrevivido por sus propios medios en Madrid de 1916 a 1921 -época axial en su vida como escritor-. Los años transcurridos durante ese autoexilio serán para él de lo más fructíferos: toda buena cosecha" (Castañón, 2010). 
de faldas"4, en palabras de Sebastián Pineda Buitrago (2014). Esto último lo confirmó el mismo Reyes, tal como se acaba de decir, en la anécdota segunda de su Anecdotario inédito (Reyes, 1994, p. 396). En la tercera, Reyes dice de Ortega que se encontraba en el ensueño provocado por su aventura, que “¡Era un adolescente! ¡Hubiera querido colgarse un letrero al cuello para que todos lo supieran!” (Reyes, 1994, p. 397). En la cuarta, cuenta de la mujer con la que estuvo el filósofo español que "Le hizo el honor a J. O. G., que se fue antes de que hubiera complicaciones" (Reyes, 1994, p. 397) y agrega que años después la vio en México y que se había vuelto "una bruja antipática y fruncida”. En la anécdota octava, Reyes narra:

Antes de ir a la Argentina, todavía envuelto en la niebla de su frío Marburgo, Ortega discutió un día con Reyes diciéndole que la virginidad de ambos cónyuges debía unirse en el matrimonio. (¡El mismo error de Víctor Hugo, a quien después nadie aguantaba!). Reyes, que había vivido más, se quedó asombrado. Pero Pepe fue luego a Buenos Aires y allá descubrió la elegancia, la voluptuosidad, el flirt y el pecado (!). Y volvió imposible, exhibiendo sus tratos con Mme. Kohertaler y haciendo creer que se había acostado en Buenos Aires con todas. (Reyes, 1994, p. 399)

Este es el Ortega y Gasset con el que trató Reyes. Ya habíamos visto algunos juicios del pensador mexicano sobre la visita del filósofo español a Argentina, pero esta anécdota es aún más reveladora de su personalidad y de las consecuencias que tuvieron en su filosofía los viajes a Argentina. Si bien las anécdotas son una serie de indiscreciones, ¿en dónde más conocemos a los hombres sino en la vida que ocultan, en sus indiscreciones?, ¿qué más circunstancia que esas que se llaman indiscreciones? Por último, la anécdota séptima cuenta un enojo de Ortega y Gasset con Reyes. En un teatro español, mientras hablaban, el mexicano, que era Encargado de Negocios de México, ve al Ministro de Cuba de ese entonces, Mario García Kohly, y va a su encuentro para arreglar no sé qué asunto diplomático. Ortega y Gasset se lo tomó a mal y le reclamó casi enseguida y muchos años después, ya en Argentina, a lo cual Reyes le dijo: "usted ha estado tantos años cultivando esta llaga, ahora sí me va usted a oír”. El filósofo español era rencoroso. Ya Reyes había notado la amargura con la que volvió de su primer viaje a Argentina.

4 "José Ortega y Gasset fue el que más apoyó a Reyes una vez que este se radicó en Madrid. Lo invitó a escribir al diario El Imparcial, al semanario España, después le dio columna semanal en el periódico El Sol" (Pineda Buitrago, 2014). 
Luego de su estancia, Ortega y Gasset salió de Argentina sin despedirse de Reyes, después de lo que hizo por él. Este último, perdonándole la grosería, le hizo llegar al barco una carta en la que manifestaba su comprensión. Después volvió a escribirle para confiarle sus cuitas en relación con la vida literaria argentina (Corral, 2011) e, implícitamente, lo absolvió de su falta, real o imaginaria. "En esto, la lealtad de Reyes hacia Ortega, quien había sido su protector durante los años difíciles en España, queda exenta de toda sospecha” (Castañón, 2010). La relación, empero, empezó a enfriarse a raíz de la publicación que hizo Ortega y Gasset de un ensayo sobre Goethe, en 1932, que hirió e indignó a Reyes por la ligereza y la soberbia con que el ensayista español trataba al maestro alemán.

Ortega y Gasset abrió de nuevo la herida, cuando en 1947 acusó a Reyes de tener "gestecillos de aldea" con los exiliados españoles ante un periodista de El Universal. García (2000) desarrolla en detalle el asunto en su artículo "Reyes y Ortega y Gasset: nuevas huellas de un largo malentendido”, con ocasión de la publicación del intercambio epistolar entre Reyes y Juan Guerrero Ruiz, coordinada por José Luis Bernal. García cuenta que Armando Chávez Camacho, corresponsal y periodista, en 1947, entrevistó a Ortega y Gasset, para el periódico El Universal ${ }^{5}$. En esa entrevista el filósofo español hizo un comentario despectivo sobre Reyes:

— ¿Tiene amigos en México?

-Tenía. Como Alfonso Reyes.

—Pues, ¿qué le ha hecho Alfonso Reyes, maestro?

—Nada concreto ni personal. Pero ha hecho tal porción de tonterías...

— ¿Como cuáles, maestro?

Un ademán de disgusto y desprecio es rubricado con estas palabras:

-Gestecillos de aldea.

El artículo de Armando Chávez causó revuelo entre los exiliados españoles quienes se decantaron por Reyes. José Gaos publicó su "Carta abierta a Alfonso Reyes” en

5 "La verdad sobre España". El Universal 15,'IX-47 (citado en García, 2000).

6 La "Carta abierta" se publicó en la recopilación de obras completas de José Gaos que hizo la Universidad Nacional Autónoma de México, en el volumen 19, titulado Epistolario y papeles privados (1999). 
El Nacional (México, 21 de septiembre de 1947), en la que rompe relaciones con Ortega y Gasset y le da la razón a Reyes. Wilberto Cantón publicó su polémica "La verdad sobre Ortega y Gasset”, también en El Nacional (México, 10 a 13 de octubre de 1947) con opiniones de Juan Larrea, Eduardo Nicol, José E. Iturriaga y Leopoldo Zea, quien llamó a Ortega y Gasset "enemigo de la americanidad". Reyes le dirigió a Guerrero Ruiz, con quien mantuvo una nutrida correspondencia, el 14 de abril de 1949, una carta en la que expresaba que

\begin{abstract}
Esas salidas amargas de José [Ortega y Gasset] me han dolido, claro está; pero no me alejan del cariño y del respeto que le debo, a pesar de su manifiesta ingratitud. Como él nunca contestó a mi carta, la carta que le puse a raíz de esas indiscreciones a que usted se refiere, le envío aquí una copia, solo para "su gobierno", como suele decirse. (Bernal, 1993, p. 87)
\end{abstract}

Esa carta de la que habla Reyes, que Ortega y Gasset no contestó, está fechada el 17 de septiembre de 1947. En ella más bien culpa al periodista y dice que de las palabras atribuidas "no quiero tomarlas en cuenta. No quiero, aun cuando a usted se le hayan podido escapar en su actual situación de amargura". Le cuenta el revuelo que han causado sus palabras entre sus amigos comunes y entre los mismos discípulos de Ortega y Gasset, y, por supuesto, entre "los perros rabiosos". Y agrega:

Mi único delito consiste en haber procurado un techo para aquellos compañeros que usted mismo educó y embarcó en la aventura, pues solo me he ocupado en los que pertenecían a nuestra familia; no en los profesionales de la pasión pública, que se han hartado de echármelo en cara. [...] Yo estoy seguro de que usted está mal informado a mi respecto, y que de otra suerte, sería el primero en aprobarme. Mire bien hacia los horizontes, por sobre las bardas de la "aldea" [...] No quise que ellos sufrieran lo que yo había sufrido, ellos que un día compartieron allá conmigo sus escasos recursos. Respecto a usted, no me confunda en el montón de los que han aprovechado el momento para atacarlo a mansalva. He respetado su dolor en silencio [...] Por más que usted se esfuerce, no podrá usted borrarme de su conciencia. Una sola palabra de

La carta muestra la tortura de Gaos porque, abiertamente, rompe relaciones con Ortega y Gasset. El autor comienza aludiendo que conoce a ambos y que le da la razón a Reyes. Cuestiona al filósofo español, especialmente por su posición en el franquismo. Un facsímil electrónico de la carta puede encontrarse en http://www.filosoficas.unam.mx/ gaos/fondo/catalogo-resultados2.php?Carpeta=47 
usted, de rectificación o esclarecimiento, le devolverá a usted la alegría de ver que mi recuerdo, cuando se le aparezca y lo visite, le sonríe como en los tiempos mejores. ¿Será posible que un hombre de su talla desoiga esta reclamación? (García, 2000, p. 73)

Ortega y Gasset desoyó la reclamación. Guerrero Ruiz le respondió a Reyes, el 5 de mayo de 1949, diciéndole que su nobleza y generosidad no merecían el silencio de Ortega y Gasset. Reyes respondió con agradecimiento por haber comprendido su carta “a José”. Un año después, en 1950, el 31 de julio, Reyes dirigió otra carta a Guerrero Ruiz pidiéndole que entregara una misiva a Ortega y Gasset, si no le incomodaba, fechada el mismo día. En ella le dice al filósofo español que necesita una palabra, solo una, de comprensión y afecto y que no tiene empacho de decir que le hace falta como parte de un conjunto armonioso, "del orbe de ideas y emociones en que aliento". Le dice que relee sus obras (García, 2000, p. 73). Guerrero Ruiz, el 15 de agosto de 1950, comunica a Reyes que no ha encontrado a Ortega y Gasset y que desea que reciba la respuesta que se merece. Todo indica que el español recibió la misiva y no respondió. Reyes mantuvo su respeto y admiración por Ortega y Gasset, apoyó la causa en México que buscaba darle al filósofo español el premio Nobel y, en 1955, estuvo al pendiente de su salud. García termina su artículo con estas palabras: "No parece impropio recordar estos rasgos de carácter del gran homme de lettres americano" (García, 2000, p. 73).

Nunca aclaró a qué se refería Ortega y Gasset. Pineda Buitrago (2014) especula que pudo referirse a que Reyes, a través del asilo a los exiliados, buscaba justificar el gobierno de Cárdenas. Ya Octavio Paz le había criticado al regiomontano que condescendía excesivamente con los políticos. Como sea, frente a los hechos recién relatados, Castañón afirma: "Con la distancia de los años se puede pensar que acaso Jorge Luis Borges tenía razón, y que Alfonso Reyes era un escritor muy superior, humana y literariamente más generoso que el susceptible José Ortega y Gasset” (Castañón, 2010). Pero no nos dejemos llevar por las vísceras, siguiendo el ejemplo de don Alfonso.

\section{Treno para Ortega y Gasset}

En 1956, Reyes publicó en Cuadernos Americanos “Treno para José Ortega y Gasset”, donde afirma: 
Una frase cruel, una queja, valen entonces lo mismo que vale un saludo, lo mismo que vale un abrazo. Y, a la hora de las cuentas finales, el inmenso saldo positivo hace todavía más lamentable la desaparición de aquel polo que, acaso de lejos, nos equilibraba y nos sostenía. Perdemos en José Ortega y Gasset a un escritor que ha dejado un rastro de fuego en la lengua y en la mente de nuestro siglo; a un filósofo imperial, no por la coherencia sistemática de un Kant o de un Hegel - a que él nunca quiso sujetarse-, sino por el altivo señorío de sus concepciones, la actitud orgullosa y la varonil trascendencia; a un pensador que de mil modos llegó a superar a sus maestros y hasta dio al mundo la expresión auténtica de algunas nociones que aún latían en la nebulosa; a un artista en quien jamás desmayó la soberbia voluntad de forma. Era hombre de ánimo solemne que luchó siempre contra las travesuras de la ironía y del humorismo, sus dos verdaderos adversarios; de una sensibilidad tan aguda que solía herirse con su propio aguijón o, mejor, que acabó atravesándose con su espada; de una honda capacidad moral que, por ser tan honda, se desgarraba entre los ideales teóricos y los apremios del deber cívico, por manera que iba y venía como el péndulo electrizado de saúco, sin poder resignarse nunca a lo que hay de transacción en la acción. En su temperamento se combatían patéticamente la mundanidad y la austeridad. Codiciado por todas las Musas a un tiempo, cada una de sus virtudes o excelencias parecía celosa de las demás. Cuando hayan corrido los años, operando su justicia de larga vista sobre las desigualdades y accidentes y demás miserias del acontecer cotidiano, esta imagen se levantará entre las más altas de España, no lo dudo.

El caballero de la inteligencia, montado en su pluma de oro como una figura mitológica, escapa ya a nuestra dimensión y se aleja de nosotros con la velocidad de la luz. Pronto será un nombre el que fue nuestro camarada de trinchera y con quien alguna vez cambiamos los pases honrosos del acero. Él quiso extrañárseme un día. Pero sabía bien a qué atenerse, y cuando su España padeció y yo me apresuré a ofrecerle mi casa, me escribió así: "Agradecí muy vivamente su cariñosa carta, que me trae su vieja amistad. Siempre en lo recóndito contaba con ella". Yo quiero evocar sobre su tumba las palabras de Horacio a Hamlet, envolviendo así en cortesías poéticas las asperidades de la desgracia: "Buenas noches, dulce príncipe: los coros de ángeles arrullen tu sueño”. (Reyes, 1989, pp. 386-388) 
Se trata, por supuesto, de un "canto fúnebre" por la muerte de su amigo. Reyes nunca dejó de considerarlo como tal, a pesar de las circunstancias. El Treno enaltece a ese príncipe, filósofo imperial de altivo señorío por sus concepciones, de actitud orgullosa y varonil trascendencia. Para Reyes - aunque no siempre estuvo de acuerdo con sus juicios, como cuando habló de Goethe-, Ortega y Gasset, como se vio cuando se recordaban las palabras de Borges, fue un maestro que dio al mundo la expresión auténtica de algunas nociones que aún latían en la nebulosa; fue un artista en quien jamás desmayó la soberbia voluntad de la forma.

\section{Conclusión}

Me propuse indagar en la relación entre Reyes y Ortega y Gasset, en cómo se convirtió en una amistad reacia y en un largo malentendido. Un vínculo que no solo se detiene en las influencias intelectuales, sino que va hasta el encuentro personal, en donde se da la circunstancia que hace a cada uno. Se descubrió, en este trabajo y para mi gusto, una faceta poco conocida del pensador español, que no solo tuvo que ver con su influencia en la filosofía mexicana, ya que esta ha sido ampliamente estudiada, pero no así la amistad que guardó con el insigne literato y diplomático mexicano, Reyes, desde la perspectiva de este último. Se descubrió, pues, cómo esa amistad, que degeneró en un largo malentendido, pero que fue circunstancia propia para ambos, los marcó. Al final de la vida solo queda el recuerdo y el "saldo positivo", como dice Reyes, que ha de permanecer por encima de las desavenencias y hace lamentable la pérdida de un filósofo que tanto influyó y del cual se recuerdan sus obras que aún siguen siendo influyentes. Quede para otra ocasión la discusión sobre el caso de Goethe, pues ya me he extendido demasiado en esta relatoría, que puede llevarnos a otras reflexiones y quizás a otra toma de postura.

\section{Referencias}

Bernal, J. L. (1993). Alfonso Reyes y Juan Guerrero Ruiz: diplomacia poética y amistad epistolar. Boletín de la Fundación Federico García Lorca, 13-14, 71-90.

Borges, J. L. (1998). Cómo conocí a Alfonso Reyes. En F. Garrido (ed.), Alfonso ReyesJorge Luis Borges. La máquina de pensar y otros diálogos literarios (pp. 147-148). Ciudad de México: Fondo de Cultura Económica, Tusquets. 
Castañón, A. (1988). Alfonso Reyes, caballero de la voz errante. Ciudad de México: Joan Boldó i Climent.

Castañón, A. (2006). Días de exilio/ Correspondencia entre María Zambrano y Alfonso Reyes (1939-1959). Letras Libres. Recuperado de https://www.letraslibres.com/ mexico/libros/dias-exilio-correspondencia-entre-maria-zambrano-y-alfonsoreyes-1939-1959

Castañón, A. (2010). Ortega y Gasset. Letras Libres. (Fragmento del prólogo al diario de Alfonso Reyes (1927-1930) que próximamente publicará El Colegio de México). Recuperado de https://www.letraslibres.com/mexico-espana/ortega-y-gasset

Corral, R. (2011). Alfonso Reyes en Libra y Sur. Ciudad de México: Colegio de México.

García, C. (2000). Reyes y Ortega y Gasset: nuevas huellas de un largo malentendido. Revista de la Universidad de México, 595, 72-74.

García, C. (2006). Reyes y Ortega, un largo malentendido. Apéndice al epistolario, Alfonso Reyes/Juan Guerrero Ruiz (1949-1950). Revista de Occidente, 300, 121-128.

Gómez Martínez, J. L. (1987). La presencia de Ortega y Gasset en el pensamiento mexicano. Nueva Revista de Filología Hispánica, 35, 197-221. Recuperado de http://www.ensayistas.org/critica/mexico/gomez/G-MOrtega.htm

Enríquez Perea, A. (2006). Estudio preliminar. En Días de exilio. Correspondencia entre María Zambrano y Alfonso Reyes 1939-1959 (pp. 25-158). Ciudad de México: Taurus, Colegio de México.

Lasaga Medina, J. (2003). José Ortega y Gasset (1883-1889). Vida y filosofía. Madrid: Biblioteca Nueva, Fundación José Ortega y Gasset.

Lipp, S. (1980). Leopoldo Zea. From "Mexicanidad" to a philosophy of history. Waterloo: Wilfrid Laurier University.

Medin, T. (1994). Ortega y Gasset en la cultura hispanoamericana. Ciudad de México: Fondo de Cultura Económica.

Ortega y Gasset, J. (1964) [1914]. Meditaciones del Quijote. Madrid: Espasa-Calpe. Ortega y Gasset, J. (1966) [1918]. El espectador I. Madrid: Espasa-Calpe. 
Pineda Buitrago, S. (2014). Incendiada mesa sobre el exilio español en México. Recuperado de http://motivosdeproteo.blogspot.mx/2014/05/incendiada-mesasobre-el-exilio-espanol.html

Ramos, S. (1976) [1943]. Historia de la filosofía en México. Ciudad de México: Universidad Nacional Autónoma de México.

Reyes, A. (1989). Treno para José Ortega y Gasset. En Marginalia. Obras completas de Alfonso Reyes (pp. 386-388). Ciudad de México: Fondo de Cultura Económica.

Reyes, A. (1994). Anecdotario de José Ortega y Gasset. En Anecdotario inédito (19141959). Obras completas de Alfonso Reyes XIII (pp. 396-399). Ciudad de México: Fondo de Cultura Económica.

Reyes, A. (1995a). Apuntes sobre José Ortega y Gasset. En Los dos caminos. Obras completas de Alfonso Reyes (pp. 258-265). Ciudad de México: Fondo de Cultura Económica.

Reyes, A. (1995b). Historia de un siglo. Las mesas de Plomo. En Obras completas de Alfonso Reyes, t. v. (pp. 11-397). Ciudad de México: Fondo de Cultura Económica.

Reyes, A. (1997). La última Tule. En Obras completas x. Ciudad de México: Fondo de Cultura Económica.

Romanell, P. (1952). Making of the Mexican mind: A study in recent Mexican thought. Lincoln: University of Nebraska Press.

Romanell, P. (1960). Ortega en México: tributo a Samuel Ramos. Diánoia, 6, 170-180.

Romanell, P. (1975). Samuel Ramos on the philosophy of Mexican culture: Ortega and Unamuno in Mexico. Latin American Research Review, 10(3), 81-101.

Zea, L. (1956). Ortega el americano. Cuadernos Americanos, 85, 132.

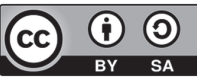

